\title{
Foot Health and Elevated Body Mass Index
}

\author{
by H.F. Jelinek ${ }^{1 \otimes}$, D. Fox ${ }^{2}$
}

The Foot and Ankle Online Journal 2 (8): 4

Objective: Investigate the relationship between the subcategories included in the Foot Health Status Questionnaire (FHSQ) and body mass index (BMI).

Design: Cross-sectional study of people attending a general health screening clinic.

Subjects: Fifty participants aged between 40 and 60 years filled out the FHSQ and were included in this study. These were divided into the three groups according to the BMI classification of underweight to Class 3 obesity.

Measurements: Demographic variables, blood pressure, BMI as well as medical history were recorded. Relationships between the subcategories of the FHSQ and BMI were investigated. All statistics were deemed significant if $\mathrm{p}<0.05$.

Results: We found that there is a significant correlation between BMI and foot pain ( $\mathrm{p}=0.047)$, foot function (p $=0.004)$, footwear $(\mathrm{p}=0.007)$ and general foot health $(\mathrm{p}=0.013)$.

Conclusion: The FHSQ is an internally consistent, all in one foot health and function assessment tool, which indicated significant impact of BMI on pain, foot function and foot health, as well as choice of foot wear. These issues can ideally be addressed by primary care physicians to improve health and quality of life for people that are overweight through effective weight loss programs.

Keywords: Obesity, foot health, Body Mass Index, Foot Health Status Questionnaire.

$\mathrm{O}$ besity is a significant health problem and the incidence of the condition is increasing. Studies by the World Health Organization have found more than one billion adults are overweight (body mass index $[\mathrm{BMI}]>25$ ) and at least 300 million of them are clinically obese (BMI >30). ${ }^{1}$ In Australia, the levels of obesity have been increasing by about one percent per year since 1980 .

\footnotetext{
Address correspondence to: Herbert F. Jelinek, email: hjelinek@csu.edu.au

1,2 School of Community Health, Diabetes Complications Screening Research Initiative (DiScRi), Charles Sturt University, Albury, NSW 2640,Australia.
}

\section{Effect of obesity on the foot}

Obesity leads to an increase in the occurrence of diverse diseases either independently or in association with other diseases and exacerbates disease progression, as well as adversely affecting foot function. ${ }^{2.3}$ Increased weight on the feet significantly increases contact areas, with increased pressure on these areas leading to increased foot problems such as pain, vascular and neuropathic disease, deformity and joint mobility. ${ }^{4,5,6}$ The Foot Health Status Questionnaire (FHSQ) measures foot specific health related quality of life incorporating the domains of functional ability, social functioning psychological wellbeing, somatic sensation (e.g. pain), and life satisfaction. $^{7}$ 


\begin{tabular}{|l|l|l|l|}
\hline & Female & Male & Average \\
\hline$n$ & 35 & 15 & 50 \\
\hline $\begin{array}{l}\text { Mean } \pm \text { SD } \\
\text { (Age, years) }\end{array}$ & $51.5 \pm 5.7$ & $53.8 \pm 5.4$ & $2.2 \pm 5.6$ \\
\hline $\begin{array}{l}\text { Mean } \\
(\text { BMI) }\end{array}$ & $33.7 \pm 9.0$ & $30.6 \pm 4.8$ & $32.7 \pm 8.0$ \\
\hline
\end{tabular}

Table 1 Participant characteristics.

The advantage of this questionnaire is that it is internally consistent and includes both physical and psychological variables. The focus of this project was to identify if an association exists between an increased body mass index and the four domains of the Foot Health Status Questionnaire.

\section{Foot Health Status Questionnaire}

The FHSQ is comprised of three sections. Questions in section one span the four domains of foot health: foot pain, foot function, footwear, and general foot health. Psychometric evaluation of the FHSQ found that the tool demonstrated a high degree of content, criterion, and construct validity and test-retest reliability. ${ }^{7}$

\section{Methodology}

The research project was approved by the Charles Sturt University Ethics in Human Research Committee. Participants were selected via stratified random sampling from the Allied Health and Diabetes Screening Program database. Individuals had the questionnaire explained and any other questions answered prior to completing the FHSQ.

Participants completed the FHSQ version 1.03 . $^{7}$ Missing items in the questionnaires (when fewer than $50 \%$ of the items for any one scale were missing) were assigned with the average value of the completed items for that scale as suggested in the instructions. ${ }^{8}$

\begin{tabular}{|l|l|l|}
\hline FHSQ Domain & $\begin{array}{l}\text { Spearman's } \\
\text { rho }\end{array}$ & P value \\
\hline Foot pain & -173 & 0.027 \\
\hline Foot function & -370 & 0.004 \\
\hline Footwear & -344 & 0.007 \\
\hline General foot health & -313 & 0.013 \\
\hline
\end{tabular}

Table 2 Correlation between FHSQ domains and BMI.

Statistical analysis was undertaken using Spearman's correlation coefficient for non-normally distributed data. Significance level was set at $\mathrm{p}<0.05$ for a one tailed test.

\section{Results}

Data from 50 participants who had completed the FHSQ was analysed. Overweight was taken as a BMI greater than 25. Participant's characteristics are presented in Table 1.

\section{Body Mass Index and FHSQ scores}

The relationship between BMI divisions and FHSQ domain scores were analysed using Spearman's rho correlation coefficient as the data was not normally distributed. There was a significant negative Spearman's rho correlation coefficient between increased BMI and foot pain, $r(47)=-27, \mathrm{p}<0.05$, foot function, $r(47)=-37, \mathrm{p}<0.01$, footwear, $r(47)=$ -34, $\mathrm{p}<0.01$, and general foot health, $r(47)=-31$, $\mathrm{p}<0.05$ (Table 2). These results indicate that as BMI increases the foot health domain scores decrease. 


\section{Discussion}

Several studies and different questionnaires have addressed foot function and foot health. However previous work has not utilised the FHSQ as a tool, which combines both function and psychological aspects of foot health.

Landorf and Keenan compared the Foot Function Index to the FHSQ, as measures of health related quality of life. These authors suggested that the FHSQ be viewed as the preferred questionnaire when evaluating health related quality of life where there is no marked impairment or disability.

The findings of the study reported here suggest that obesity has a significant effect on the level of foot pain independent of condition $(\mathrm{p}<0.05)$. An increased BMI was also found to be associated with a reduction in perceived foot function by the participants using the FHSQ $(p<0.01)$. This is in line with previous work but does not require separate test batteries to be performed for foot pain and foot function. ${ }^{4,10}$ Han, et al., quantified the impairment of quality of life attributable to body fatness using the SF-36 Health Survey and concluded that quality of life measures were related to body mass index, and that participants with a high body mass index were more likely to have poor physical functions that limited many common basic activities of daily living. ${ }^{11}$ The current study showed that comfortable and appropriate footwear was perceived as more difficult to find as BMI increased as extra wide shoe fittings are not always commercially available $(p<0.01) .{ }^{12}$ Finally, BMI has an impact on general health as reported by previous authors. $^{13,14}$

The relationship between obesity and foot-specific health is unclear. The FHSQ is capable of measuring physical and social functioning as subjectively reported by individual, therefore the four domains of the FHSQ may be considered suitable to determine if a relationship exists between obesity, as measured by BMI, and foot-specific health. Similarly covariates, such as age, gender, BMI and diabetes mellitus, account for much more of the variance explained by the foot function domain of the FHSQ than do foot disorders themselves. ${ }^{10}$

\section{Conclusion}

The findings of the present study and similar findings from other authors clearly support the concept that obesity influences foot function. The main aim of this study was to identify if a relationship existed between increased BMI and foot health as measured by the four domains of the FHSQ, foot pain, foot function, footwear, and general foot health.

This study showed that obesity has a significant effect on the level of foot pain, normal foot function, the adequate fit of footwear, and general foot health as determined by the FHSQ.

\section{References}

1. WHO. World Health Organisation, Global strategy on diet, physical activity and health. Available at: http://www.who.int. Accessed 14 October, 2008.

2. Hills AP, Henning EM, Byrne NM, Steele JR: The biomechanics of adiposity - structural and functional limitations of obesity and implications for movement. Obesity Reviews 3: $35-43,2002$.

3. Rejeski WJ, Focht BC, Messier SP, Morgan T, Pahor M, Penninx B: Obese, older adults with knee osteoarthritis: weight loss, exercise and quality of life. Health Psychology 21: $419-$ 426, 2002.

4. Gravante G, Russo G, Pomara F, Ridola C: Comparison of ground reaction forces between obese and control young adults during quit standing on a baropodometric platform. Clinical Biomechanics 18: 780 - 782, 2003.

5. Lievense AM, Bierma-Zeinstra SMA, Verhagen AP, van Baar ME, Verhaar JAN, Koes BW: Influence of obesity on the development of osteoarthritis of the hip: a systematic review. Rheumatology 41: 1155 - 1162, 2004.

6. van Schie CHM, Boulton AJM: The effect of arch height and body mass on plantar pressure. Wounds 12 (4): 88 - 95, 2000. 
7. Bennett PJ, Patterson CP, Wearing S, Baglioni T: Development and validation of a questionnaire designed to measure foot-health status. Journal of the American Podiatric Medical Association 88: 419 - 428, 1998.

8. Bennett PJ, Patterson CP, Dunn JE: Health related quality of life following podiatric surgery. Australasian Journal of Podiatric Medicine 32 (3): $164-173,2001$.

9. Landorf KB, Keenan A-M: An evaluation of two footspecific, health-related quality-of-life measuring instruments. Foot and Ankle International. 23: 538 - 546, 2002.

10. Badlissi F, Dunn JE, Link CL, Keysor JJ, McKinlay JB, Felson DT: Foot musculoskeletal disorders, pain and footrelated functional limitation in older persons. Journal of the American Geriatrics Society 53: 1029 - 1033, 2005.

11. Han TS, Tijhuis MAR, Lean MEJ, Seidell JC: Quality of life in relation to overweight and body fat distribution American Journal of Public Health 88: 1814 - 1820, 1998.

12. Burns SL, Leese GP, McMurdo ME: Older people and ill fitting shoes. Postgraduate Medical Journal 78: 344 - 346, 2002.

13. Fontaine KR, Bartlett SJ, Barofsky I. Health-related quality of life among obese persons seeking and not currently seeking treatment. International Journal of Eating Disorders 27: 101 - 105, 2000 .

14. Hakim Z, Wolf A, Garrison LP: Estimating the effect of changes in body mass index on health state preferences. Pharmacoeconomics 20: 393 - 404, 2002. 